\title{
ALTURA DE MUDAS DA Tibouchina granulosa COGN. (MELASTOMATACEAE) ESTIMADA POR REDES NEURAIS ARTIFICIAIS
}

\author{
Jéssica Cristina Barbosa Ferreira ${ }^{1}$; Bruno Oliveira Lafetá ${ }^{2}$; Tamires Mousslech Andrade Penido ${ }^{3}$; Paulo \\ Modesto de Campos ${ }^{4}$; Pedro Mendes Castro ${ }^{5}$
}

\section{RESUMO}

O objetivo do presente trabalho foi avaliar a eficiência da estimação da altura de mudas da Tibouchina granulosa em função do diâmetro do coleto, sob diferentes composições de substrato, empregando Redes Neurais Artificiais (RNA). Foram selecionadas 72 mudas produzidas via tubetes para a repicagem em baldes de 25 litros. Adotou-se delineamento experimental inteiramente casualizado, com três repetições, sendo os tratamentos constituídos por quatro composições de substrato. Cada unidade experimental foi composta por seis mudas. Aos 13 meses de idade foram mensurados o Diâmetro à Altura do Coleto (DAC) e a altura total $(\mathrm{H})$ de todas as mudas. Foram treinadas 200 RNA para estimar a H, sendo 100 Multilayer Perceptron (MLP) e 100 Radial Basis Function (RBF). As variáveis utilizadas como entrada das RNA para estimação da altura das mudas foram numéricas (DAC e H) e categórica (T: Substrato 1 - T1; Substrato 2 - T2; Substrato 3 - T3 e Substrato 4 - T4). Conclui-se, assim, que a modelagem por RNA utilizando arquitetura MLP é adequada e precisa para estimar a altura de mudas da Tibouchina granulosa.

Palavras-chave: Inteligência artificial; Relações hipsométricas; Vegetação urbana.

\section{SEEDLINGS HEIGHT OF THE Tibouchina granulosa COGN. (MELASTOMATACEAE) ESTIMATED BY ARTIFICIAL NEURAL NETWORKS}

\begin{abstract}
This study aimed to evaluate the estimation efficiency for seedlings height of the Tibouchina granulosa in function of root collar diameter, under different substrate compositions, using Artificial Neural Networks (ANN). Were selected 72 seedlings produced via plastic tubes for transplanting in buckets of 25-liter. The experiment was established in a completely randomized design with three repetitions, being the treatments constituted of four substrate compositions. Each experimental unit was composed of six seedlings. At 13 months of age the root collar diameter (DAC) and total height (H) of all seedlings were measured. Were trained 200 ANN to estimate H, 100 Multilayer Perceptron (MLP) and 100 Radial Basis Function (RBF). The variables used as input of ANN to seedlings height estimation were numerical (DAC and H) and categorical (T: Substrate 1 T1; Substrate 2 - T2; Substrate 3 - T3 and Substrate 4 - T4). It's concluded that ANN modeling using MLP architecture is appropriately and accurately to estimate the seedlings height of Tibouchina granulosa.
\end{abstract}

Key-words: Artificial intelligence; Hipsometric relations; Urban vegetation.

\footnotetext{
${ }^{1}$ Graduanda de Tecnologia em Silvicultura, Instituto Federal de Educação, Ciência e Tecnologia de Minas Gerais-IFMG, São João Evangelista, MG, Avenida Primeiro de Junho, n 1043, Centro, bruno.lafeta@ifmg.edu.br

jessicacbf.ifmg@gmail.com

${ }^{2}$ Engenheiro Florestal, Mestre em Ciência Florestal, Professor de Tecnologia em Silvicultura, Instituto Federal de Educação, Ciência e Tecnologia de Minas Gerais-IFMG, São João Evangelista, MG, Avenida Primeiro de Junho, n 1043, Centro, bruno.lafeta@ifmg.edu.br

${ }^{3}$ Graduanda de Engenharia Florestal, Universidade Federal dos Vales do Jequitinhonha e Mucuri-UFVJM, Diamantina, MG, Rodovia MGT 367 - Km 583, ${ }^{\circ}$ 5000, Alto Jacuba, penidotma@gmail.com

${ }^{4}$ Especialista em Fruticultura Comercial, Instituto Federal de Educação, Ciência e Tecnologia de Minas Gerais-IFMG, São João Evangelista, MG, Av. Primeiro de Junho, n 1043, Centro, paulo.campos@ifmg.edu.br

${ }^{5}$ Engenheiro Ambiental, Arborista Especialista em Sistemas Elétricos, Companhia Energética de Minas Gerais-CEMIG, Belo Horizonte, MG, Av Barbacena, ${ }^{\circ}$ 1200/11\%/A1, Santo Agostinho, pedro@cemig.com.br

${ }^{6}$ recebido em 24/01/2014 e aceito para publicação em 15/03/2014
} 
A arborização das cidades proporciona benefícios sociais, ecológicos e estéticos para a sociedade (ROCHA et al., 2004). É uma prática que requer um planejamento prévio a fim de evitar prejuízos às calçadas, tubulações subterrâneas, edifícios, redes elétricas (GONÇALVES et al., 2004). A utilização adequada de plantas na arborização é essencial, o tamanho das mudas pode influenciar o desenho urbano.

A produção de mudas destinadas a projetos paisagísticos é uma atividade sustentável, que busca aumentar a área verde em cidades, evitando ilhas de calor e propiciando condições ambientais mais agradáveis para sociedade (ROSSATTO et al., 2008). A caracterização da altura e diâmetro das mudas é uma etapa importante para a determinação do volume, atributos estes que auxiliam o dimensionamento de covas e melhor local para o plantio nas zonas urbanas.

Uma espécie muito utilizada na ornamentação de centros urbanos é a Tibouchina granulosa Cogn. (Melastomataceae), popularmente conhecida como quaresmeira, que possui tolerância à luminosidade direta e rusticidade (CÉZAR, et al., 2009). Além disso, a quaresmeira pode ser indicada para a arborização de ruas estreitas e sob redes elétricas, melhorando a qualidade do ar devido à capacidade de suas copas em reduzir material particulado (LOPES et al, 2005; ZAMPIERI et al., 2013).

Normalmente, medidas de diâmetro são fáceis e rapidamente obtidas em vegetais, porém as de altura são mais demoradas e, consequentemente, mais dispendiosas para a coleta de dados. A relação entre o diâmetro e a altura de vegetais é denominada de hipsométrica (CAMPOS; LEITE, 2009). O uso de equações hipsométricas é frequente. Na busca por novas opções para a estimação eficiente e segura da altura destaca-se a inteligência artificial. As Redes Neurais Artificiais (RNA) representam uma nova abordagem para o desenvolvimento de modelos preditivos, capazes de aprender padrões complexos e tendências de dados, mesmo que não sejam normais (HAYKIN, 2001; SCRINZI et al., 2007).

As RNA são modelos computacionais que simulam a estrutura e o processamento do sistema nervoso humano, estabelecendo relações matemáticas entre variáveis dependentes e independentes (GORGENS et al., 2009; MAEDA et al., 2009). A arquitetura da rede influencia o processamento dos dados de entradas, permitindo aproximações lineares ou não na camada intermediária (LAFETÁ et al., 2012). As arquiteturas mais comuns são as de base radial (Radial Basis Function ou RBF) e as de múltiplas camadas (Multilayer perceptron ou MLP).

O desempenho das RNA têm sido superior aos modelos de regressão face às suas próprias características de adaptabilidade dos pesos das conexões às modificações do ambiente, tolerância a falhas e ruídos, analogia neurobiológica, resolução de problemas complexos e habilidade de aprendizagem (BINOTI et al., 2010; BINOTI, 2010).

A eficiência das RNA pode ser avalida usando um tipo de validação cruzada comumente designado como holdout method (HAYKIN, 2001). Fundamentando no partionamento do conjunto de dados em subconjuntos mutualmente exclusivos, em que parte dos dados são utilizados no treinamento e o restante, no teste e na validação. Este procedimento é importante para testar a capacidade de classificar corretamente padrões não incluídos no treinamento, e, portanto, na definição 
da rede com melhor capacidade de generalização (FERNANDES et al., 2004).

Estudos que abordem relações hipsométricas e técnicas estatísticas avançadas podem auxiliar no estabelecimento de critérios práticos na arborização urbana. Assim, este trabalho teve como objetivo avaliar a eficiência da estimação da altura de mudas da Tibouchina granulosa em função do diâmetro do coleto, sob diferentes composições de substrato, empregando RNA.

\section{MATERIAIS E MÉTODOS}

O experimento foi conduzido em ambiente a céu aberto no Viveiro de Mudas do Instituto Federal de Educação, Ciência e Tecnologia de Minas Gerais Campus São João Evangelista-MG (IFMG/SJE) à $22^{\circ} 13^{\prime} 16$ “de latitude Sul e 544ㅇ'20 de longitude Oeste. O clima da região é temperado chuvosomesotérmico e classificado como Cwa pelo sistema de Köppen (com inverno seco e verão chuvoso), a precipitação média anual é de $1400 \mathrm{~mm}$ e a temperatura média anual de $21^{\circ} \mathrm{C}$ (BRAGA et al., 1999).

Foram selecionadas 72 mudas de Tibouchina granulosa produzidas via tubetes para a repicagem em baldes de 25 litros. As mudas se encontravam sadias, livres de injúrias causadas por fitopatógenos e com um comprimento de parte área entre 20 e $25 \mathrm{~cm}$

Adotou-se delineamento experimental inteiramente casualizado, com três repetições, sendo os tratamentos assim constituídos: T1 - Substrato 1 (79,2 \% de terra de subsolo, 10,0 \% de moinha de carvão, $10,0 \%$ de substrato comercial, 0,13 \% de osmocote 19:6:10 e 0,67 \% de NPK 6:30:6); T2 Substrato 2 (73,54 \% de terra de subsolo, 7,33 \% de moinha de carvão, 18,33 \% de substrato comercial, 0,13\% de osmocote 19:6:10 e 0,67\% de NPK 6:30:6); T3 - Substrato 3 (49,87\% de terra de subsolo, 49,33 \% de esterco bovino curtido, 0,13\% de osmocote 19:6:10 e 0,67 \% de NPK 6:30:6) e T4 - Substrato 4 (49,60 \% de terra de subsolo, 24,80 \% de substrato comercial, 24,80 \% de esterco bovino curtido, $0,13 \%$ de osmocote $19: 6: 10$ e $0,67 \%$ de NPK 6:30:6). Cada unidade experimental foi composta por seis mudas. Aos 13 meses de idade foram mensurados o Diâmetro à Altura do Coleto (DAC) e a altura total (H) de todas as mudas.

O treinamento de uma rede neural artificial, também denominado aprendizagem, consiste no ajuste iterativo dos parâmetros da rede (pesos e bias) através de um algoritmo de aprendizagem (MAEDA et al., 2009). Neste processo os dados de treinamento (conjunto de exemplos) são apresentados a uma arquitetura pré-estabelecida, ou seja, um determinado número de arranjos de neurônios em camadas. E o algoritmo de treinamento extrai características a fim de representar a informação fornecida e desempenhar uma determinada tarefa. As variáveis utilizadas como entrada das RNA para estimação da altura das mudas foram numéricas $\left(\mathrm{DAC}_{(\mathrm{mm})}\right.$ e $\left.\mathrm{H}_{(\mathrm{cm})}\right)$ e categórica (T: 1 - T1; 2 - T2; 3 - T3 e 4 - T4).

Foram utilizadas redes anteroalimentadas (feedforward), treinadas por meio do algoritmo da retropropagação do erro (backpropagation), ou seja, durante o treinamento da rede foram realizados cálculos partir da camada de entrada da rede para a de saída e o erro propagado para camadas anteriores. Em todos os préprocessamentos foram realizadas a normalização e equalização dos dados. Os dados foram divididos 
em grupos de treinamento (80,0 \% das amostras), teste (10,0 \% das amostras) e validação (10,0 \% das amostras) utilizando o método randômico de amostragem.

Foram treinadas 200 RNA para estimar a H, sendo 100 Multilayer Perceptron (MLP) e 100 Radial Basis Function (RBF). Foi utilizado o modelo heurístico backward elimination, conforme descrito por Cerqueira et al. (2001). Dessas RNA foram selecionadas uma de cada tipo com base nos desvios dos valores estimados e observados. Um dos problemas mais comuns verificados no treinamento das RNA é o overfitting. Buscando evitá-lo, o treinamento das redes foi interrompido no momento em que o erro começou aumentar, conforme BRADSHAW et al. (2002) e MAEDA et al. (2009).

O número ótimo de camadas intermediárias e de neurônios por camada, geralmente, não é conhecido a priori. Uma vez definidos a arquitetura e os parâmetros de aprendizado, a rede neural artificial é treinada de forma iterativa (BLACKARD; DEAN, 1999). Portanto a definição da arquitetura das redes foi otimizada pela ferramenta Intelligent Problem Solver (IPS) do software Statistica 7.0 (STATSOFT, 2007).

Os pontos que extrapolaram a tendência geral de cada tratamento não foram eliminados a fim de verificar a capacidade das redes neurais artificiais em lidar com outliers ou ruídos. A avaliação da acurácia e da precisão e a comparação do treinamento das redes foi realizada conforme os critérios definidos por Lafetá et al. (2012). Os critérios se basearam no erro relativo, na raiz do quadrado médio do erro (RMSE), na tendenciosidade (Bias), no teste $t$ pareado a 5,0\% de significância estatística e na análise de gráficos de dispersão e distribuição da frequência percentual de resíduos percentuais.

O treinamento, teste e validação das redes foram realizados com auxílio do software Statistica 7.0 (STATSOFT, 2007).

\section{RESULTADOS}

As redes apresentaram funções de ativação não lineares nas camadas intermediárias (Tabela 1). O comportamento sigmoidal na camada de saída foi observado somente na MLP. A fase de treinamento das redes com arquitetura MLP e RBF tiveram 20 e 182 ciclos, respectivamente.

Tabela 1. Caracterização das Redes Neurais Artificiais (RNA) para a estimação da altura de mudas da Tibouchina granulosa a serem destinadas à arborização urbana

\begin{tabular}{ccccc}
\hline \multirow{2}{*}{ RNA } & $\mathrm{n}$ & Arquitetura & \multicolumn{2}{c}{ Função de Ativação } \\
\cline { 4 - 5 } & & & Intermediária & Saída \\
\hline MLP & 72 & $5-11-1$ & Exponencial & Logística \\
RBF & 72 & $5-12-1$ & Gaussiana & Identidade
\end{tabular}

MLP = Multilayer perceptron. RBF = Radial Basis Function $. \mathrm{n}=$ número de observações.

Os valores médios de RMSE para a MLP e RBF foram de $9,01 \%$ e $12,52 \%$, respectivamente
(Tabela 2). Em geral, durante o treinamento foram observados baixos RMSE e Bias. Maiores 
amplitudes dos erros relativos foram observadas na RBF em todas as fases de processamento. Os dados observados e estimados foram estatisticamente semelhantes entre si pelo teste $t$ em ambas as redes construídas.

Tabela 2. Precisão das Redes Neurais Artificiais (RNA) para a estimação da altura de mudas da Tibouchina granulosa a serem destinadas à arborização urbana

\begin{tabular}{clcccccc}
\hline \multirow{2}{*}{ RNA } & \multirow{2}{*}{ Fases } & RMSE\% & Bias\% & \multicolumn{3}{c}{ Erros relativos (\%) } & \multicolumn{2}{c}{ teste $t$} \\
\cline { 6 - 7 } & & & & Máximo & Media & Mínimo & $p$ \\
\hline \multirow{2}{*}{ MLP } & Treinamento & 8,21 & $-0,15$ & 29,46 & 0,85 & $-15,14$ & 0,8902 \\
& Teste & 9,94 & 3,20 & 12,80 & $-2,16$ & $-11,17$ & 0,3989 \\
& Validação & 8,89 & $-0,52$ & 29,15 & 2,33 & $-11,40$ & 0,8818 \\
\hline \multirow{2}{*}{ RBF } & Treinamento & 9,08 & 0,00 & 43,45 & 0,96 & $-16,74$ & 0,9993 \\
& Teste & 11,93 & 0,55 & 24,78 & 1,07 & $-12,72$ & 0,9060 \\
& Validação & 16,55 & $-5,17$ & 73,60 & 9,96 & $-3,76$ & 0,4141 \\
\hline
\end{tabular}

MLP = Multilayer perceptron. $\mathrm{RBF}=$ Radial Basis Function.

As redes tiveram poucos ruídos ao assumir como outliers as linhas de dados que, após o processamento apresentaram estimativa da altura superior do que 2,0 unidades de desvio-padrão em relação ao dado observado correspondente (Figura 1). A rede MLP apresentou homogeneidade de variâncias. Os dados estimados e observados pelas redes selecionadas estão apresentados na Figura 2. As redes geraram estimativas estatisticamente similares. Embora uma desvantagem observada tenha sido a perda na precisão à medida que diminuiu o DAC das mudas. 
Figura 1. Representação da distribuição dos erros percentuais em função do Diâmetro à Altura do Coleto (DAC) e classes de erro para as Redes Neurais Artificiais (RNA) construídas para estimar a altura de mudas da Tibouchina granulosa a serem destinadas à arborização urbana. MLP = Multilayer perceptron. $\mathrm{RBF}=$ Radial Basis Function

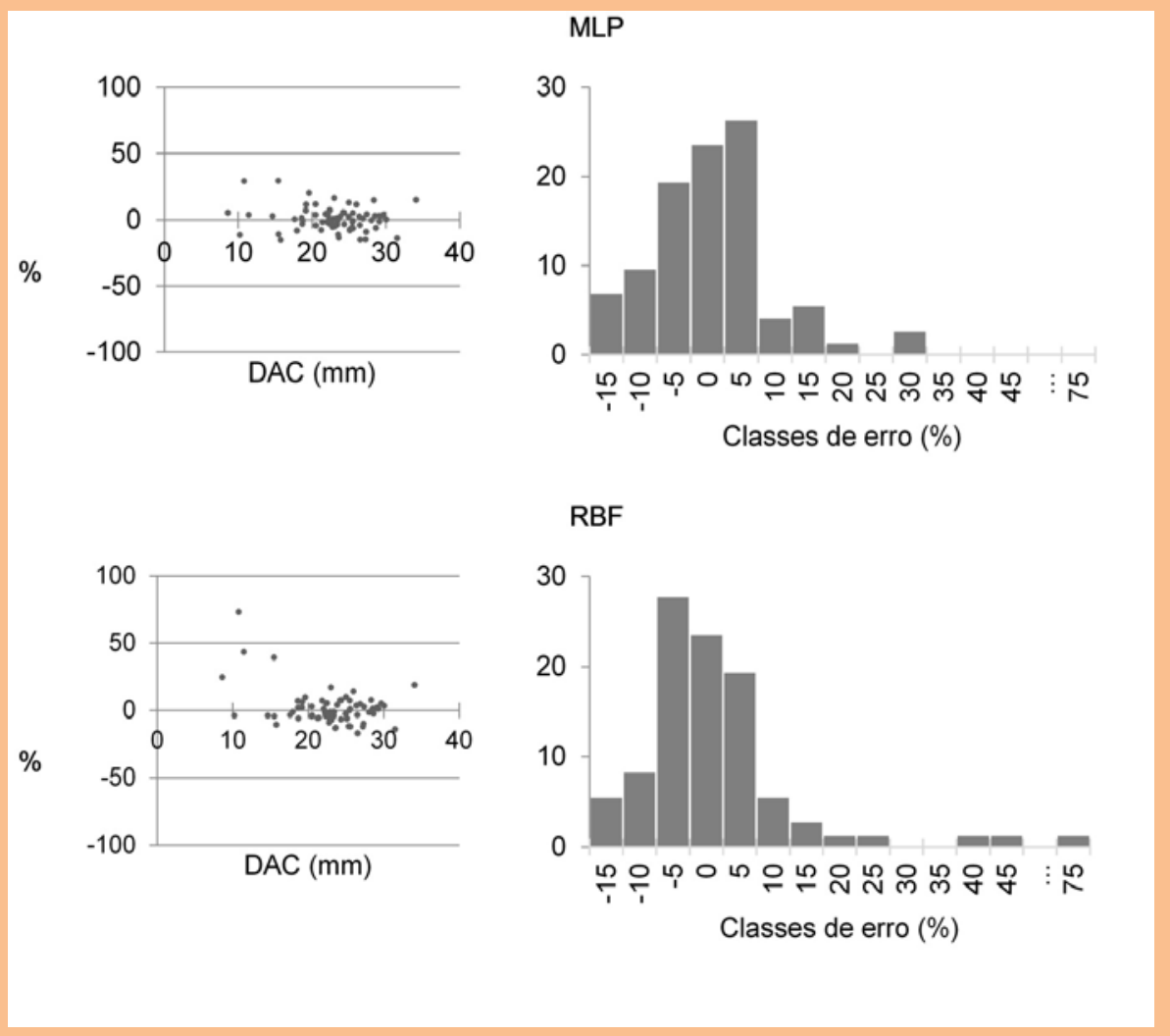

Figura 2. Estimação da altura de mudas da Tibouchina granulosa a serem destinadas à arborização urbana pelas redes MLP (Multilayer perceptron) e RBF (Radial Basis Function)
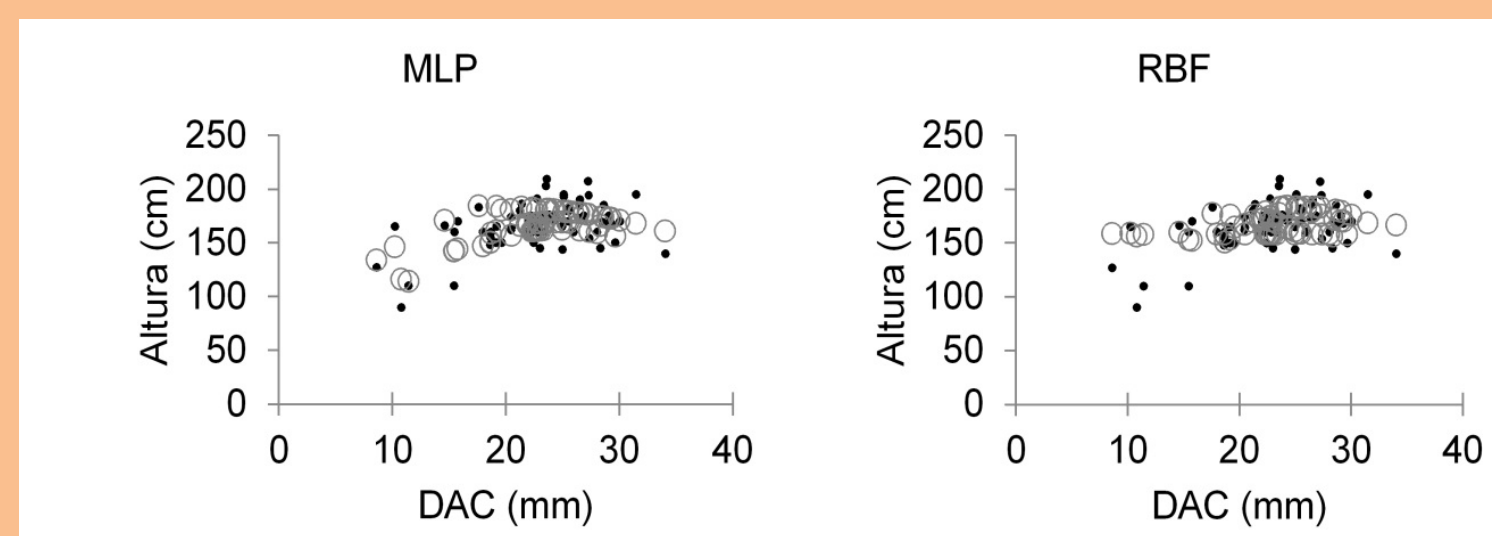

- Observado $\circ$ Estimado 
A tendência não linear observada em ambas as redes (Tabela 1) possibilitou que as camadas sucessivas tenham capacidade de solucionar problemas de maior ordem no espaço de entrada (BRAGA et al., 2007). As redes MLP e a RBF geraram campos receptivos globais e locais, respectivamente. A rede $\mathrm{RBF}$ expressou maior complexidade face ao maior número de neurônios na camada intermediária. Salienta-se que a definição da arquitetura das redes, ou seja, número de camadas e o número de neurônios por camada foi otimizada pela ferramenta IPS.

Diante da complexidade de se relacionar o diâmetro e a altura de mudas sob diferentes composições de substrato, a precisão das redes foi considerada satisfatória. Embora a rede MLP tenha apresentado um bom treino e uma pior validação, as RMSE e Bias variaram pouco entre as fases de processamento e as amplitudes dos erros relativos foram baixas (Tabela 2). Portanto, este desempenho não necessariamente foi gerado por uma memorização excessiva dos dados de treinamento. Fato este que corrobora com a falta de significância estatística no teste $t$ pareado e a utilização de um número reduzido de ciclos pela rede. Aplicou-se a técnica de interrupção precoce e normalização dos dados como heurística. A heurística possibilita uma aproximação da solução ótima (SOARES et al, 2011; STATISTICA, 2007). Entretanto, o baixo número de ciclos pode ter comprometido o desempenho e capacidade computacional da rede RBF, caracterizando um subtreinamento ou underfitting (HAYKIN, 2001), pois apresentou maior variação entre as fases de processamento (treinamento, teste e validação).

A rede MLP apresentou arquitetura mais simples (menos neurônios na camada intermediária), menos desvios e tendeciosidades, expressando melhor capacidade de aprendizado (Figura 1). Deve-se ressaltar que a arquitetura MLP constrói aproximadores globais, sendo composta por uma camada de entrada, uma ou mais camadas intermediárias e uma camada de saída (SOARES et al., 2011). Mesmo sendo observados poucos ruídos, a habilidade de lidar com outliers durante o processo de ajuste de seus pesos através de um algoritmo de aprendizagem foi comprovado (Figura 2). Esses desvios foram uniformemente distribuídos entre as observações.

Uma desvantagem observada foi a perda na precisão à medida que diminuiu o DAC das mudas, principalmente na rede $\mathrm{RBF}$, salienta-se que a variância total de ensaios experimentais é atribuída em parte a fatores controlados de causas conhecidas e independentes e outra, a fatores não controlados de natureza aleatória, portanto não estão isentos de erros (LAFETÁ et al., 2012). A rede com arquitetura MLP demonstrou que pode captar o realismo biológico dos dados, aprender e generalizar o conhecimento assimilado para um conjunto de dados desconhecidos não empregados durante o treinamento, ou conjuntos teste e validação (Figura 2).

A capacidade de generalização e conectividade da arquitetura MLP permitiu que se utilizasse apenas uma rede para realizar a estimação simultânea da altura das mudas de Tibouchina granulosa independente da composição do substrato estudado. Ao contrário, o uso dos métodos tradicionais implicaria em realização de análise de regressão individual da altura para cada composição de substrato.

A altura de mudas é essencial para o planejamento da arborização em centros urbanos e o método 
estatístico proposto pelo presente trabalho forneceu estimativas precisas, além de tornar a obtenção destes resultados relacionados a biometria florestal mais rápida, menos onerosa e dispendiosa economicamente, além de ser menos laboriosa pela possibilidade de utilização de dados diamétricos independente da composição do substrato utilizado.
O uso da arquitetura MLP em RNA pode ser recomendado para estimar a altura das mudas de Tibouchina granulosa a partir do diâmetro do coleto, independente da composição dos substratos estudados pelo presente trabalho. Esta metodologia pode fornecer subsídios importantes para a estimação da altura de mudas de outras espécies florestais, nativas ou exóticas, aplicando RNA.

\section{CONCLUSÃO}

A modelagem por redes neurais artificiais com arquitetura Multilayer Perceptron (MLP) demonstrou-se adequada e precisa para estimar a altura de mudas da Tibouchina granulosa a partir do diâmetro do coleto, independente da composição do substrato em estudo.

\section{AGRADECIMENTOS}

Ao Instituto Federal de Educação, Ciência e Tecnologia (IFMG) - Campus de São João Evangelista-MG e à Companhia Energética de
Minas Gerais (CEMIG) por todo apoio logístico e financeiro para a realização do presente trabalho.

\section{REFERÊNCIAS BIBLIOGRÁFICAS}

BINOTI, D. H. B.; LEITE, H. G.; NOGUEIRA, G. S.; SILVA, M. L. M.; GARCIA, S. L. R.; CRUZ, J. P. Uso da função Weibull de três parâmetros em um modelo de distribuição diamétrica para plantios de eucalipto submetidos a desbaste. Revista Árvore, Viçosa, v. 34, n.1, p. 147-156, 2010.

BINOTI, M. L. M. S. Redes neurais artificiais para prognose da produção de povoamentos não desbastados de eucalipto. Viçosa, 2010. 54f. Dissertação (Mestrado em Ciência Florestal) - Universidade Federal de Viçosa, Viçosa, 2010.

BLACKARD, J. A.; DEAN, D. J. Comparative accuracies of artificial neural networks and discriminant analysis in predicting forest cover types from cartographic variables. Computers and Electronics in Agriculture, Amsterdam, v. 24, p. 131-151, 1999. 
BRADSHAW, C. J. A.; DAVIS, L. S.; PURVIS, M.; ZHOU, Q.; BENWELL, G. L. Using artificial neural networks to model the suitability of coastline for breeding by New Zealand fur seals (Arctocephalus forsteri). Ecological Modelling, Amsterdam, v. 148, p. 111-131, 2002

BRAGA, A. P.; CARVALHO, A. C. P. L. F.; LUDERMIR, T. B. Redes neurais artificiais: Teoria e aplicações. 2 ed. Rio de Janeiro: LTC, 2007. 226 p.

BRAGA, F. A.; BARROS, N. F.; SOUZA, A. L.; COSTA, L. M. Características ambientais determinantes da capacidade produtiva de sítios cultivados com eucalipto. Revista Brasileira de Ciência do Solo, Viçosa, v. 23, n.2 p.291-298, 1999.

CAMPOS, J. C. C.; LEITE, H. G. Mensuração Florestal. 3 ed., Viçosa: Editora UFV, 261 p., 2009.

CERQUEIRA, E. O.; ANDRADE, J. C.; POPPI, R. J. Redes neurais e suas aplicações em calibração multivariada. Química Nova, São Paulo, v. 24, n. 6, p. 864-873, 2001.

CÉZAR, T. M.; SOUZA, F. C.; MACIEL, R. T.; DEMBISKI, W.; ZUFFELLATO-RIBAS, K. C. RIBAS; L. L. F.; KOEHLER, H. S. Estaquia e alporquia de Tibouchina fothergillae (D. C.) Cogn. (Melastomataceae) com a aplicação de ácido naftaleno acético. Revista Scientia Agraria, Curitiba, v. 10, n. 6, p. 463-468, 2009.

FERNANDES, A. M.; UTKIN, A. B.; LAVROV, A. V.; VILAR, R. M. Development of neural network committee machines for automatic forest fire detection using lidar. Pattern Recognition, Amsterdam, v. 37, p. 2039-2047, 2004.

GONÇALVES, E. O.; PAIVA, H. N.; GONÇALVES, W.; JACOVINE, L. A. G. Avaliação qualitativa de mudas destinadas à arborização urbana no estado de Minas Gerais. Revista Árvore, Viçosa, v. 28, n. 4, p. 479-486, 2004.

GORGENS, E. B.; LEITE, H. G.; SANTOS, H. N.; GLERIANI, J. M. Estimação do volume de árvores utilizando redes neurais artificiais. Revista Árvore, Viçosa, v. 33, n. 6, p. 1141-1147, 2009.

HAYKIN, S. Redes Neurais: Princípios e prática. 2 ed. Porto Alegre: Bookman, 2001; 900 p.

LAFETÁ, B. O.; SANTANA, R. C.; NOGUEIRA, G. S.; PENIDO, T. M. A.; COUTO, L. Área foliar específica e clorofila em eucalipto estimadas por redes neurais artificiais. Biomassa \& Energia, Viçosa, v. 5, n. 1, p. 6775, 2012.

LOPES, J. C.; DIAS, P. C.; PEREIRA, M. D. Maturação fisiológica de sementes de quaresmeira. Pesquisa Agropecuária Brasileira, Brasília, v. 40, n. 8, p. 811-816, 2005.

MAEDA, E. E.; FORMAGGIO, A. R.; SHIMABUKURO, Y. E.; ARCOVERDE, G. F. B.; HANSEN, M. C. Predicting forest fire in the Brazilian Amazon using MODIS imagery and artificial neural networks. 
International Journal of Applied Earth Observation and Geoinformation, Amsterdam, v. 11, p. 265-272, 2009.

ROCHA, R. T.; LELES, P. S. S.; OLIVEIRA NETO, S. N. Arborização de vias públicas em nova iguaçu, RJ: o caso dos bairros rancho novo e centro. Revista Árvore, Viçosa, 28, n. 4, p. 599-607, 2004.

ROSSATTO, D. R.; TSUBOY, M. S. F.; FREI, F. Arborização urbana na cidade de Assis-sp: uma abordagem quantitativa. Revista Sociedade Brasileira de Arborização Urbana, Piracicaba, v. 3, n. 3, p. 1-16, 2008.

SCRINZI, G.; MARZULLO, L.; GALVAGNI, D. Development of a neural network model to update forest distribution data for managed alpine stands. Ecological Modelling, Amsterdam, v. 206, p. 331-346, 2007.

SOARES, F. A. A. M. N.; FLÔRES, E. L.; CABACINHA, C. D.; CARRIJO, G. A.; VEIGA, A. C. P. Recursive diameter prediction and volume calculation of eucalyptus trees using Multilayer Perceptron Networks. Computers and Electronics in Agriculture, Amsterdam, v. 78, p. 19-27, 2011.

STATSOFT, INC. Statistica (data analysis software system), version 7. Disponívelem: $<$ http://www.statsoft.com>, 2007.

ZAMPIERI, M. C. T.; SARKIS, J. E. S.; PESTANA, R. C. B.; TAVARES, A. R.; MELO-DE-PINNA, G. F. A. Characterization of Tibouchina granulosa (Desr.) Cong. (Melastomataceae) as a biomonitor or air pollution and quantification of particulate matter adsorbed by leaves. Ecological Engineering, Amsterdam, v. 61, p. 316-327, 2013. 